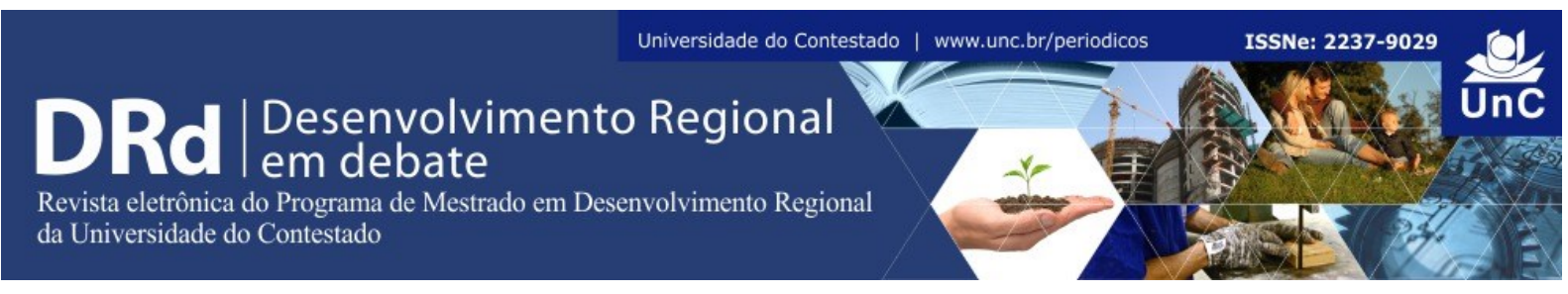

\title{
SISTEMA SÓCIO ECOLÓGICO E AMBIENTALISMO NO CONTEXTO EMPRESARIAL
}

\author{
Ronaldo Leão de Miranda ${ }^{1}$ \\ Gilberto Friedenreich dos Santos ${ }^{2}$ \\ Eliane Maria Martins ${ }^{3}$
}

\begin{abstract}
RESUMO
O desenvolvimento sustentável ideal é aquele capaz de suprir as necessidades do presente sem comprometer a capacidade de atender as necessidades das futuras gerações. Neste âmbito, entram em discussão as práticas organizacionais, que de uma forma ou de outra, com o passar do tempo vêm se adaptando às novas legislações, principalmente as ambientais, cujo propósito é alcançar a sustentabilidade em todas as suas dimensões. Para tanto, este trabalho tem por objetivo refletir e dialogar sobre as discussões que estão ligadas ao sistema sócio ecológico e ao ambientalismo no contexto empresarial. Metodologicamente, trata-se de um estudo exploratório, descritivo e bibliográfico. Dessa forma, elaborar e estabelecer planos de desenvolvimento socioeconômico de forma sustentável tornou-se um grande desafio da atualidade devido à pluralidade de atores e contextos territoriais. As estratégias empresariais precisam de novas táticas multidisciplinares, para que assim, se consiga soluções admissíveis quanto aos problemas ambientais. Neste sentido, entender os fundamentos da resiliência é um processo importante, no que tange o desenvolvimento de estratégias de conservação ambiental.
\end{abstract}

Palavras-chave: Sistema Sócio Ecológico. Ambientalismo Empresarial. Práticas Ambientais.

\section{ECOLOGICAL PARTNER SYSTEM AND ENVIRONMENTALISM IN THE BUSINESS CONTEXT}

\begin{abstract}
Ideal sustainable development is one that can meet the needs of the present without compromising the ability to meet the needs of future generations. In this context, organizational practices enter into discussion, which in one way or another, over time have been adapting to new legislation, especially environmental legislation, whose purpose is to achieve sustainability in all its dimensions. Therefore, this work aims to reflect and dialogue

\footnotetext{
${ }^{1}$ Graduado em Administração de Empresas pela Universidade Regional Integrada do Alto Uruguai e das Missões, mestrando em Desenvolvimento Regional pela Universidade Regional de Blumenau - Blumenau, Santa Catarina, Brasil. E-mail: 1ronaldo815@gmail.com

${ }^{2}$ Graduado e Mestre em Geografia pela Universidade Federal de Santa Catarina, Doutor em Geografia pela Universidade de São Paulo, professor do Programa de Pós-Graduação em Desenvolvimento Regional da Universidade Regional de Blumenau - Blumenau, Santa Catarina, Brasil. E-mail: gilbertofrieden@gmail.com ${ }^{3}$ Graduada em Economia pela Universidade da Região de Joinville, Mestre e doutoranda em Desenvolvimento Regional pelo Programa de Pós-Graduação em Desenvolvimento Regional da Universidade Regional de Blumenau, Blumenau, Santa Catarina, Brasil. E-mail: emtins@hotmail.com
}

DRd - Desenvolvimento Regional em debate (ISSNe 2237-9029)

v. 7, n. 2, p. 188-205, jul./dez. 2017. 
on the discussions that are linked to the socio-ecological system and environmentalism in the business context. Methodologically, this is an exploratory, descriptive and bibliographic study. In this way, developing and establishing socio-economic development plans in a sustainable way has become a major challenge today because of the plurality of actors and territorial contexts. Business strategies need new multidisciplinary tactics, so that acceptable solutions to environmental problems can be achieved. In this sense, understanding the fundamentals of resilience is an important process in the development of environmental conservation strategies.

Keywords: Ecological Partner System. Business Environmentalism. Environmental Practices.

\section{INTRODUÇÃO}

O desenvolvimento sustentável ideal é aquele capaz de suprir as necessidades do presente sem comprometer a capacidade de atender as necessidades das futuras gerações. Dentro desta abordagem entra em discussão as práticas organizacionais, que de uma forma ou de outra, com o passar do tempo vêm se adaptando às novas legislações, principalmente as ambientais, cujo propósito é alcançar a sustentabilidade em todas as suas dimensões. Para Capra e Luisi (2014, p. 435) as

[...] definições de sustentabilidade são importantes exportações morais, no entanto, elas não nos dizem nada sobre como devemos construir uma sociedade sustentável. Comunidades sustentáveis desenvolvem seus padrões de vida ao longo do tempo em interação contínua com outros sistemas vivos, humanos e não humanos. Desse modo, a sustentabilidade é um processo dinâmico de coevolução em vez de um estado estático.

Este trabalho tem por objetivo refletir e dialogar sobre as discussões que estão ligadas ao sistema sócio ecológico e ao ambientalismo no contexto empresarial. Partindo deste pressuposto, gerenciar e fazer negócios na atualidade começou a demandar um modelo que pudesse conciliar o crescimento, a eficiência e a inovação das empresas com as questões inerentes à sustentabilidade. Neste caso, a sustentabilidade deixa de ser uma escolha e passa a compor um universo de estratégias corporativas com vistas a melhores resultados econômicos, sociais e ambientais, em prol da conservação do meio ambiente.

Diante do atual contexto econômico ambiental, o uso exaustivo dos recursos naturais se legitima com a ideia de crescimento econômico baseado na industrialização, na qual, se visa o lucro em cima da degradação ambiental. Voltando no tempo, buscando resgatar o contexto histórico, de como se sucedeu o crescimento econômico a partir da Revolução Industrial no final do século XVIII, nos deparamos com práticas baseadas na utilização intensiva de matérias primas (recursos naturais). Todo o uso intenso dos recursos naturais serviu de suplemento para as indústrias, perdurando esse modelo por décadas e décadas, sem que houvesse qualquer tipo de regulamentação ou controle.

Todavia, a partir do século XX, as práticas ambientais começaram a mudar, com uma conscientização ecológica, e uma defesa ferrenha dos movimentos em defesa do meio ambiente. Os governos começaram a formular e implementar políticas ligadas à proteção do 
meio ambiente, dos ecossistemas, além de multar e controlar indústrias, que de uma forma ou de outra, causaram ou ainda persistem em causar algum tipo de impacto ou danos irreversíveis ao meio ambiente.

\section{METODOLOGIA}

Para delinear a pesquisa se utilizou a taxionomia apresentada por Vergara (2010, p. 41) que classifica a pesquisa quanto aos fins e quanto aos meios.

Quanto aos fins trata-se de um estudo exploratório e descritivo de abordagem conceitual relacionadas ao sistema sócio ecológico e ao ambientalismo no contexto empresarial. Gil (2010) descreve que a pesquisa descritiva tem como objetivo a descrição das características de determinada população, tendo como finalidade a identificação de possíveis relações entre as variáveis.

Quanto aos meios de investigação, trata-se de um estudo bibliográfico, pois para descrever a literatura vigente se fez necessário à consulta em livros, artigos especializados no tema em questão, materiais disponibilizados na internet, dentre outros instrumentos de busca. Vergara (2010, p. 43) "[...] descreve que este tipo de estudo é sistematizado, no qual se desenvolve com base em material publicado, em livros, revistas, jornais, redes eletrônicas, material acessível ao público em geral”.

\subsection{DESENVOLVIMENTO EM QUESTÃO}

A abordagem sobre o conceito desenvolvimento é ampla, e que com o tempo, o conceito de desenvolvimento foi sendo ampliado, entendendo-se que este não pode ficar restrito a apenas uma área, já que é bastante complexo. Assim, o desenvolvimento contemporâneo é um processo multidimensional, que reflete interação social, econômica, política, cultural e ambiental. Dessa forma, dentre os diversos conceitos de desenvolvimento, Inayatullah (1973, p. 114) afirma que o "[...] desenvolvimento é um processo através do qual uma sociedade consegue maior controle sobre o meio, sobre o seu próprio destino político e os capacita a obter maior controle sobre si mesmo".

De outro ângulo, mas ainda na perspectiva do conceito de desenvolvimento, coloca-se em pauta que nas últimas décadas a busca pelo tal desenvolvimento se deu da pior forma, em relação ao meio ambiente. Todo o processo de industrialização e "desenvolvimento" causou profundas perdas, principalmente no que tange aos recursos naturais. O crescimento econômico colocado aqui, sempre foi visto como sendo o único e absoluto meio e fim para a promoção do desenvolvimento. Acompanhando essas transformações estruturais, numa dimensão econômica, social, ambiental, cultural, política e espacial, pode-se evidenciar que as abordagens acerca do desenvolvimento local e regional evoluíram numa perspectiva crescente. Mudanças estas que foram fundamentais em cada período, tendo presente 
características que legitimaram as reflexões e percepções acerca do desenvolvimento. Diante deste contexto, pode-se citar algumas características do conceito de desenvolvimento, ou seja, podemos compreender essa forma de mudança de um modo multidimensional, multidirecional e multissignificativo. Sachs (1993, p. 25) discorre sobre essas características no sentido de que:

Revisitando este conceito, o desenvolvimento diante de sua multidimensionalidade, abrange todo $\mathrm{o}$ aspecto de necessidades materiais e não-materiais, como corretamente enfatiza o PNUD no Relatório sobre o Desenvolvimento Humano, ainda que tal ênfase não se reflita no reducionismo de seu índice de desenvolvimento humano.

O debate sobre o tema desenvolvimento, além de rico é bastante instigador no meio acadêmico. Além disso, busca-se através desses meios, desmistificar a controvérsia que existe entre desenvolvimento e crescimento econômico, na qual é atribuído pela sociedade. Para tanto, as controvérsias relacionadas aos dois termos, Scatolin busca esclarecer, salientando que:

Conceitos como progresso, crescimento, industrialização, transformação, modernização têm sido usado frequentemente como sinônimos de desenvolvimento. Em verdade, eles carregam dentro de si toda uma compressão específica dos fenômenos, e constituem verdadeiros diagnósticos da realidade, pois o conceito prejulga, indicando em que se deverá atuar para alcançar o desenvolvimento (SCATOLIN, 1989, p. 6).

Oliveira (2002) contribui ressaltando que o desenvolvimento é o resultado do processo de mudança, na qual ocorre a partir da discussão e integração das dinâmicas de ordem econômica, política, social, espacial, cultural, dentre outras. Depois de compreender a diferença e ao mesmo tempo a relação entre crescimento e desenvolvimento, Santos et al. (2012) nos remete às origens, salientando que o termo desenvolvimento surgiu na biologia, empregado como processo de evolução dos seres vivos para o alcance de suas potencialidades genéticas, porém, incorpora-se nas teorias e práticas sociais, por meio da economia, da sociologia, da antropologia, da geografia e da ciência política.

Santos et al. (2012) pontua que na década de 1940 o desenvolvimento recebe o status de objeto de pesquisa científica com o surgimento da Economia do Desenvolvimento. Diante disso, cada vez mais os defensores do desenvolvimento regional/local tem se posicionado de forma colaborativa em relação aos debates sobre o desenvolvimento das regiões e dos países. Posições estas que visam desenvolver as atividades econômicas, sociais, ambientais, culturais, dentre outras. Quanto à perspectiva econômica, o conceito de desenvolvimento concebido no campo da economia centra-se na ideia da acumulação de riqueza e na expectativa que o futuro guarda em si a promessa de um maior bem-estar (SANTOS et al., 2012).

Para tanto, Brandão (2004, p. 58) faz uma contextualização, considerando que “[...] no auge do debate sobre desenvolvimento nacional na década de 50, bem como dos desequilíbrios regionais na década de 60, ou da questão urbana nos anos 70 e 80 viveu-se tamanho fascínio para tal problemática de discussão". O autor relata ainda, sobre como eram discutidos os temas regionais e urbanos na esfera do território, onde no que tange ao urbano, as questões passavam por investigar a dinâmica dos movimentos sociais urbanos, renda da terra urbana, marginalidade social urbana, habitação, enfim, dentre outros. Já na questão 
regional eram discutidas as origens, a lógica e o possível contraponto efetivado ou não pelas políticas estatais aos desequilíbrios entre as diversas porções territoriais (BRANDÃO, 2004).

Já nos dias atuais, “[...] embora haja a preocupação de juntar 'o regional', 'o rural' e 'o urbano', os objetos investigados são outros, muito distante da abordagem anterior, que levava em conta as questões históricas e estruturais, na qual presidiu parte importante no processo de desenvolvimento" (BRANDÃO, 2004, p. 59). Diante de tantas abordagens, o que se resume é que o desenvolvimento socioeconômico contemporâneo busca, através de conceitos que enfocam, principalmente, o local (regional), proporcionar uma melhora nas condições econômicas da região e também valorizar o indivíduo e a comunidade, ou seja, na visão atual, o principal é a valorização da vida (do ser humano), maior responsável pelas transformações sociais. Dessa forma, portanto, vale destacar que não existe uma "receita" para o desenvolvimento, pois cada macro ou microrregião apresentam diferenças regionais significantes em função da cultura, da história, da tradição local, dentre outras variáveis.

Portanto, as discussões são amplas sobre o tema, mas se vai além, onde para compreender as questões que acercam o desenvolvimento no âmbito regional, se faz necessário caracterizar os fundamentos da resiliência como um importante processo no desenvolvimento de estratégias do sistema sócio ecológico.

\section{RESILIÊNCIA DO SISTEMA SÓCIO ECOLÓGICO}

Passaram-se mais de quatro décadas desde que o termo resiliência surgiu como um conceito distinto de outros conceitos, até então associado à definição de "estabilidade". O primeiro cientista a abordar esse tema foi Holling, em seu artigo intitulado "Resilience and stability of ecological systems", publicado em 1973. Este estudo considera a resiliência como a persistência de relações num sistema, uma medida da capacidade dos sistemas em absorver alterações das suas variáveis de estado, das suas variáveis determinantes e dos seus parâmetros, continuando a perdurar no tempo.

Portanto,

O conceito de resiliência apresenta atualmente uma grande variedade de definições, provenientes de um vasto corpo de disciplinas, mas todas as noções derivam, na sua essência, de um corpo teórico baseado na teoria de sistemas e na teoria da complexidade. A sua aplicação estende-se a numerosas áreas - da Ecologia à Inovação Social - mas tem sido particularmente frutífera no domínio dos sistemas sócio ecológicos (FARRALL, 2012, p. 50).

Dentro do mesmo conceito de resiliência, a figura 1 visa ilustrar alguns dos elementos na qual abordam a resiliência enquanto abordagem conceptual integrativa, colaborativa e interdisciplinar. Essa discussão implica a uma interdisciplinaridade, ou seja, integram-se conhecimentos provenientes de múltiplas áreas temáticas (área das ciências ambientais, econômicas, dentre outras). 
Figura 1: Conceitos associados à resiliência enquanto forma de pensar.

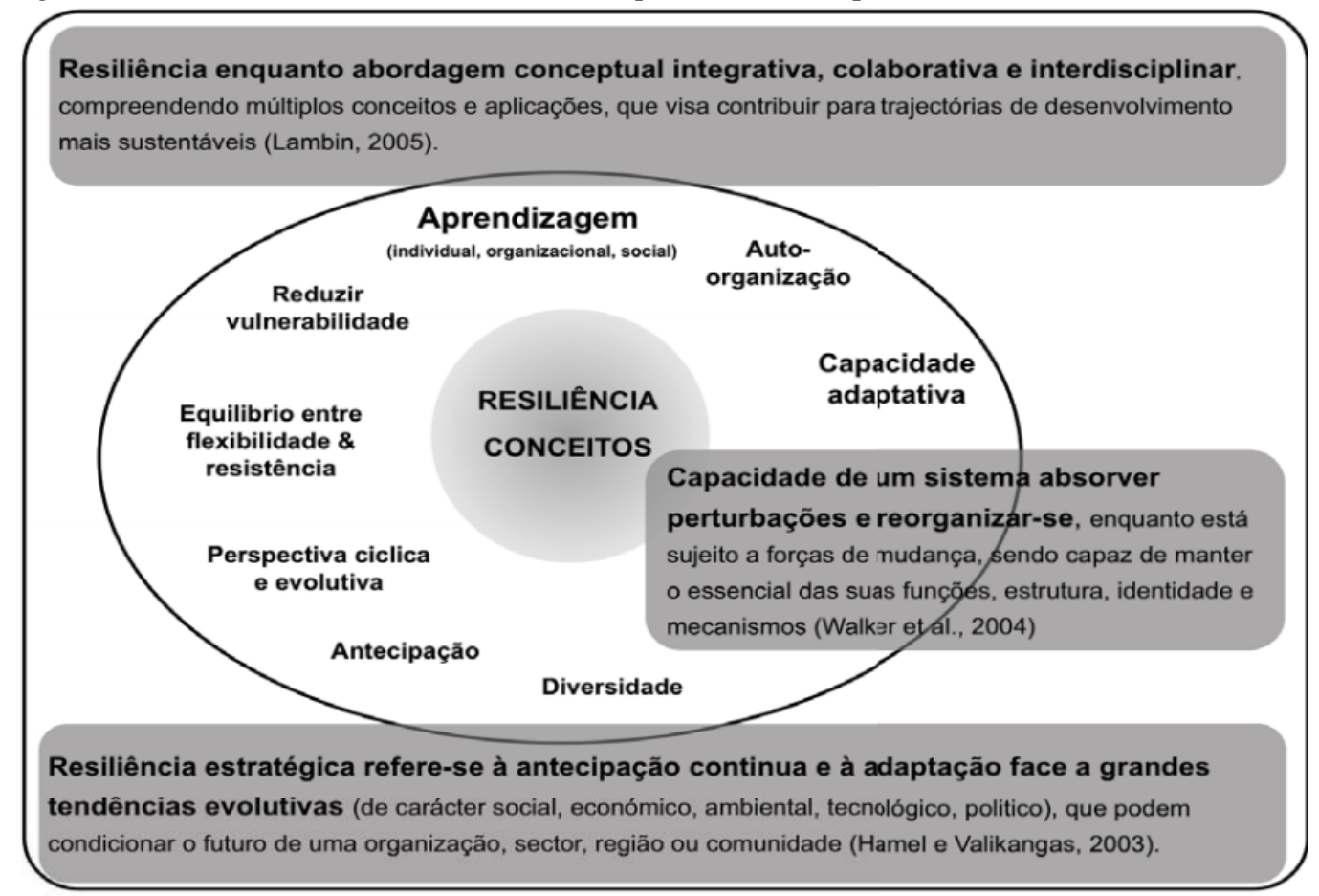

Fonte: Santos (2009, p. 35)

Colaborando com esse pensamento, Santos (2009, p. 36) discorre ainda que:

\begin{abstract}
Na perspectiva da sustentabilidade e da resiliência, uma região pode ser encarada como um sistema sócio ecológico, enquanto que por outro lado, na perspectiva das políticas de desenvolvimento, a região aspira a ser encarada como um protagonista político e econômico, cada vez mais autônomo na liderança e gestão do seu próprio processo de desenvolvimento.
\end{abstract}

Neste sentido, o sistema sócio ecológico representa uma dinâmica que é afetada por configurações sociais, econômicas e políticas, bem como por outros ecossistemas. Neste âmbito, o capital natural é um bem valioso para a humanidade e encontrar soluções sustentáveis sobre como garantir a existência das futuras gerações é um desafio que o mundo precisa enfrentar. Dado que, apesar das enormes vantagens e avanços tecnológicos, as pessoas ainda dependem enormemente da natureza e de suas condicionantes e potencialidades para uma variedade de necessidades essenciais, como água limpa e potável para consumo, agropecuária para alimentação, proteção contra perigos como secas e tempestades e uma variedade de necessidades culturais e recreativas que tem importante papel no bem-estar humano (MA - MILLENIUM ASSESSMENT, 2005). No entanto, para que estes grupos sociais estejam em sinergia para encontrar a solução de problemas comuns, há uma série de empecilhos individuais que podem minar as estratégias de uma cooperação conjunta.

O aprendizado entre diferentes atores sociais passa por diferentes estágios e pode levar a processos que incluem mudanças de valor, normas e ação coletiva. O processo está diretamente relacionado com a resiliência do sistema sócio ecológico (SSE), isto é, o exercício do aprendizado de cooperação frente às diferenças leva a um aumento da resiliência, não somente ecológico, mas também socioeconômico, pois depende da ação da coletividade plural, representada pelos usuários do sistema. A participação por meio do envolvimento ativo 
de todas as partes interessadas é considerada fundamental para a construção de resiliência sócio ecológica. Ela ajuda a construir a confiança e os relacionamentos necessários para melhorar a legitimidade de conhecimento e autoridade durante os processos de tomada de decisão, pois auxilia a detectar e interpretar perturbações, podendo ocorrer de diversas formas em um processo de gestão (BIGGS; SCHLÜTER; SCHOON, 2014).

Outro processo de desenvolvimento que considera as condições locais é conhecido como desenvolvimento territorial sustentável. O enfoque pode ser considerado como um paradigma reflexivo e de intervenção que redefine a relação ambiente e desenvolvimento (GODARD, 1997; LARRIÉRÈ; LARRIÉRÈ, 1997). Associando este pensamento ao de resiliência, verifica-se que a ampliação da participação se faz importante e deve ser realizada cuidadosamente, para não aumentar a influência de algumas partes interessadas em detrimento de outras. Trata-se de uma esfera que integra outros dois pilares da sustentabilidade, a equidade social e a viabilidade econômica. Além disso, formas fracas de cogestão, onde a participação possui pouca autoridade, mas muita responsabilidade para usuários, podem degradar a resiliência dos sistemas sócio ecológicos e os serviços dos ecossistemas produtivos.

Sabemos, porém, que a participação - e um dos elementos centrais do novo enfoque de desenvolvimento - na qual desempenhará um papel preponderante. Consequentemente, uma das principais áreas problema a ser explorada é a da participação social na produção de tecnologias apropriadas para um projeto de desenvolvimento autônomo (HERRERA, 2003, p. 45).

A participação contribui, portanto, para que o sistema sócio ecológico possua relações de interdependências na divisão do trabalho, permita ainda uma flexibilidade de transformação da produção, conforme a valorização das competências técnicas, isto é, além da capacidade de responder rapidamente às solicitações do mercado, é também a capacidade de adaptação, em termos de longo prazo, às mudanças econômicas e tecnológicas. Na literatura, as diversas formas de resiliência se traduzem em princípios, pelos quais se pode construir ou melhorar a resiliência de um sistema sócio ecológico.

Quadro 1: Os Sete Princípios de Resiliência para SSE.

\begin{tabular}{|l|l|}
\hline PRINCÍPIOS & CARACTERÍSTICAS \\
\hline $\begin{array}{l}\text { 1. Manter a } \\
\text { diversidade e } \\
\text { redundância }\end{array}$ & $\begin{array}{l}\text { Em um sistema sócio ecológico, componentes, tais como as espécies, tipos de } \\
\text { paisagem, sistemas de conhecimento, atores, grupos culturais ou instituições } \\
\text { todos oferecem diferentes opções para responder à mudança e lidar com a } \\
\text { incerteza e surpresa. }\end{array}$ \\
\hline $\begin{array}{l}\text { 2. Gerenciar } \\
\text { conectividades }\end{array}$ & $\begin{array}{l}\text { Conectividade pode ser uma coisa boa ou uma coisa ruim. Altos níveis de } \\
\text { conectividade podem facilitar a recuperação após uma perturbação, mas } \\
\text { sistemas altamente conectados também podem espalhar distúrbios mais } \\
\text { rapidamente. }\end{array}$ \\
\hline $\begin{array}{l}\text { 3. Gerenciar } \\
\text { variáveis lentas e } \\
\text { feedbacks }\end{array}$ & $\begin{array}{l}\text { Sistemas sócio ecológicos podem muitas vezes ser "configurados" de várias } \\
\text { maneiras diferentes. Em outras palavras, há muitas maneiras em que todas as } \\
\text { variáveis em um sistema podem ser conectadas e interagirem uns com os outros. } \\
\text { Essas configurações diferentes oferecem diferentes serviços dos ecossistemas. }\end{array}$ \\
\hline $\begin{array}{l}\text { 4. Adotar sistemas de } \\
\text { pensamento } \\
\text { complexo adaptativo }\end{array}$ & $\begin{array}{l}\text { Para podermos continuar a beneficiar uma gama de serviços ecossistêmicos, } \\
\text { precisamos compreender as interacções complexas e dinâmicas que existem } \\
\text { entre atores e ecossistemas em um sistema sócio ecológico. Administração com } \\
\text { base em "sistemas de pensamento complexo adaptativo", que aprecia essas } \\
\text { interações e as dinâmicas frequentemente complexas que eles criam podem } \\
\text { aumentar a resiliência dos sistemas sócio ecológicos. }\end{array}$ \\
\hline
\end{tabular}

DRd - Desenvolvimento Regional em debate (ISSNe 2237-9029)

v. 7, n. 2, p. 188-205, jul./dez. 2017. 


\begin{tabular}{|l|l|}
\hline $\begin{array}{l}\text { 5. Incentivar a } \\
\text { aprendizagem }\end{array}$ & $\begin{array}{l}\text { O conhecimento de um sistema é sempre parcial e incompleto e sistemas sociais } \\
\text { ecológicos não são exceções. Os esforços para melhorar a resiliência dos } \\
\text { sistemas sócio ecológicos devem, portanto, ser suportados pelo aprendizado } \\
\text { contínuo e experimentação. }\end{array}$ \\
\hline $\begin{array}{l}\text { 6. Ampliar a } \\
\text { participação }\end{array}$ & $\begin{array}{l}\text { A participação através do envolvimento ativo de todos os intervenientes } \\
\text { relevantes é considerada fundamental para a construção de resiliência sócio } \\
\text { ecológica. Ela ajuda a construir a confiança e relacionamentos necessários para } \\
\text { melhorar a legitimidade do conhecimento e autoridade durante os processos de } \\
\text { tomada de decisão. }\end{array}$ \\
\hline $\begin{array}{l}\text { 7. Promover sistemas } \\
\text { de governança } \\
\text { policêntricos }\end{array}$ & $\begin{array}{l}\text { A policentricidade é um sistema de governança em que vários órgãos sociais } \\
\text { interagem para fazer cumprir as regras dentro de uma arena política específica. } \\
\text { A localização é considerada como uma das melhores maneiras de conseguir } \\
\text { uma ação coletiva em face de perturbação e de mudança. }\end{array}$ \\
\hline
\end{tabular}

Fonte: Adaptado de Biggs, Schlüter e Schoon (2014)

Todos os princípios de resiliência em SSE apresentados requerem uma compreensão diferenciada de como, onde e quando aplicá-los, e como os diferentes princípios interagem e dependem uns dos outros. Para Biggs, Schlüter e Schoon (2014), simplesmente aumentar a resiliência dos ecossistemas existentes em uma paisagem pode consolidar e agravar as desigualdades, tais como: onde as comunidades urbanas pobres sofrem os efeitos de inundações, decorrentes das atividades agrícolas ou florestais em terras de propriedade privada rio acima. Existem importantes trade-offs ${ }^{4}$ entre os diferentes serviços ambientais (por exemplo, produção agrícola e da biodiversidade), e não é possível aumentar a resiliência de todos os serviços de um ecossistema de maneira simultânea. Com estas advertências em mente, os sete princípios de resiliência orientam sobre a melhor maneira de intervir e trabalhar com SSEs.

\section{PRUDÊNCIA ECOLÓGICA, EQUIDADE SOCIAL E VIABILIDADE ECONÔMICA}

As empresas são organismos responsáveis por impulsionar o crescimento econômico e cabe a elas melhorar ou expandir as disponibilidades de recursos como:

a) a adequação do tamanho e da estrutura da população; b) a modernização e a ampliação da capacidade instalada de produção; e c) a exploração das reservas naturais ocorrentes no espaço econômico, sob a condição de preservação autossustentada do meio ambiente (ROSSETTI, 2000, p. 74).

\footnotetext{
${ }^{4}$ Trade-off ou tradeoff é uma expressão que define uma situação em que há conflito de escolha. Ele se caracteriza em uma ação econômica que visa à resolução de problema, mas acarreta outro, obrigando uma escolha. Ocorre quando se abre mão de algum bem ou serviço distinto para se obter outro bem ou serviço distinto.
} 
É importante que as organizações que pensam em praticar um modo de produção sustentável incorporem as variáveis ambientais nas suas decisões de planejamento, implementação e controle, por razões econômicas e em respeito às gerações atuais e futuras.

Aos recursos disponíveis na região, torna não só esses recursos, como os conhecimentos a eles associados, uma riqueza. Pensar em formas de preservar esse patrimônio, como também a sua relação com ele têm seus produtores e consumidores, passa a ser estratégica para o desenvolvimento de tais regiões (FONSECA, 2003, p. 74 e 75).

O mundo corporativo, portanto, deve desempenhar um papel fundamental na garantia de preservação do meio ambiente, e na definição da qualidade de vida das comunidades, e de seus colaboradores. Isto porque, o campo de atuação empresarial possui uma abrangência bastante significativa por envolver grupos que afetam e são afetados pela atividade empresarial (Figura 2).

Figura 2: Envolvidos na responsabilidade social e ambiental empresarial.

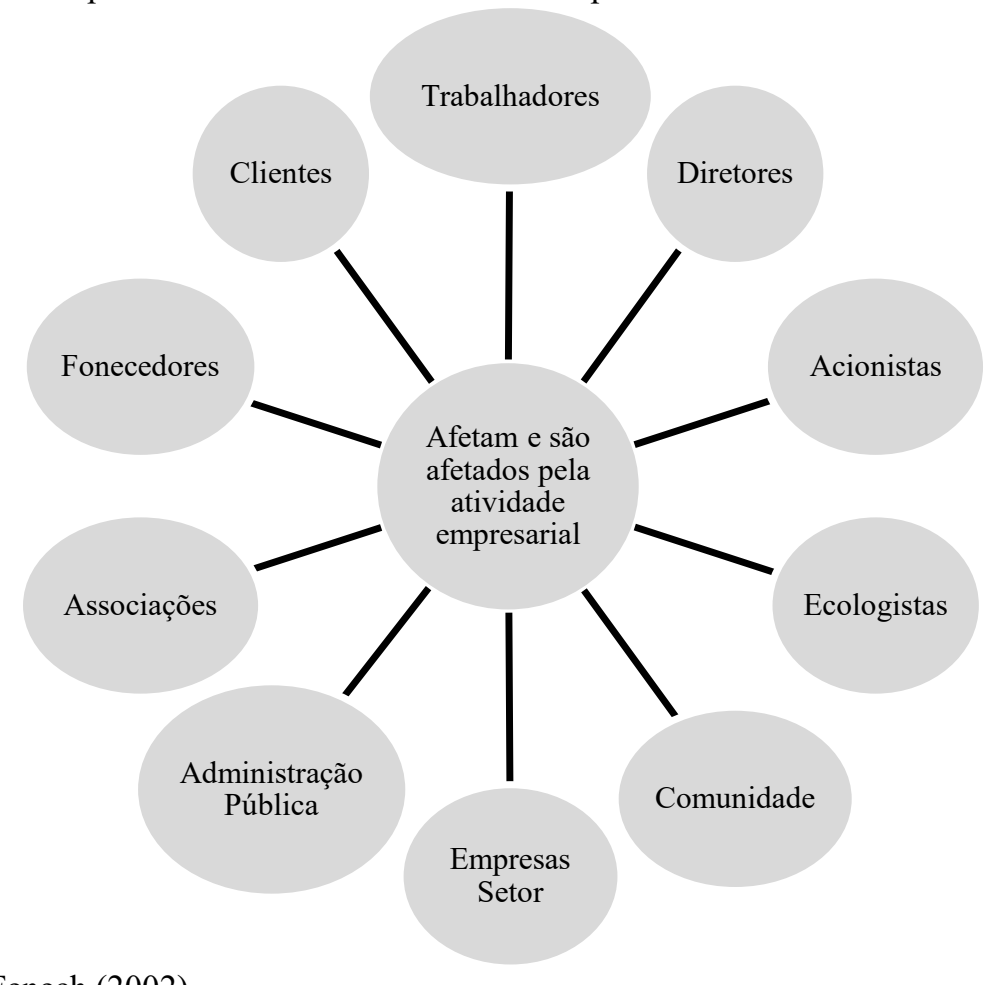

Fonte: Adaptado de Fenech (2002).

É evidente que cada um desses participantes possui um papel muito importante para a dinâmica empresarial com relação ao processo de resiliência do SSE, e concomitantemente comungam de interesses. Como se observa no quadro 2, funcionam como contrapartida por seus serviços oferecidos. 
Quadro 2: Interesse específico para cada participante.

\begin{tabular}{|l|l|}
\hline PARTÍCIPE & PRINCIPAIS INTERESSES \\
\hline 1. Trabalhadores & $\begin{array}{l}\text { Garantia de emprego. Salários. Orgulho e sentimento de dignidade. Saúde e } \\
\text { segurança no lugar no trabalho. }\end{array}$ \\
\hline 2. Comunidade local & $\begin{array}{l}\text { Riscos de saúde. Ruídos. Odores. Resíduos expelidos no solo, água e ar. } \\
\text { Conhecimento da atividade da empresa. Riscos de acidente. }\end{array}$ \\
\hline 3. Clientes e fornecedores & $\begin{array}{l}\text { Qualidade dos produtos. Preços. Segurança nos produtos. Garantia nos } \\
\text { produtos. }\end{array}$ \\
\hline 4. Administração pública & $\begin{array}{l}\text { Cumprimento da legislação. Acidentes e denúncias. Consumo de recursos. } \\
\text { Evidência de que a empresa cumpre seus compromissos ambientais. }\end{array}$ \\
\hline $\begin{array}{l}\text { 5. Entidades financeiras, } \\
\text { investidores e acionistas }\end{array}$ & $\begin{array}{l}\text { Resultados financeiros. Informações sobre responsabilidade ou obrigações } \\
\text { legais e respeito a terceiros. Custos ambientais e sua gestão. Investidores } \\
\text { ambientais. Vantagens comerciais relacionadas com a gestão ambiental. } \\
\text { Custo do não cumprimento legal. }\end{array}$ \\
\hline 6. Organizações ecológicas & $\begin{array}{l}\text { Informação ambiental no âmbito local. Impactos nos ecossistemas. Impactos } \\
\text { ambientais de produto ou serviço. }\end{array}$ \\
\hline
\end{tabular}

Fonte: Fundació Fórum Ambiental (2001)

Neste sentido, a conjuntura econômica atual é apontada por críticas da dinâmica capitalista e da economia de mercado por não mais responder aos novos desafios colocados pelo aquecimento global e ser a causa de tantas "patologias sociais". Por conta disso, faz-se necessário elencar algumas alternativas viáveis nos mais variados aspectos que envolvem a justiça social, a prudência ecológica, e a eficiência econômica. As decisões, então, precisam ser tomadas com base em riscos e em incertezas, convergindo com os anseios e perspectivas da sociedade.

Assim, junto com a análise de receita antes mencionada, os reguladores devem também avaliar os impactos econômicos e sociais, traduzindo-os, sempre que possível, em termos dos valores monetários que iriam afetar os principais grupos econômicos e sociais relacionados com aquela política (MOTTA, 2006, p.104).

Trata-se de saber quais são os impactos positivos e negativos que cada decisão pode acarretar, tanto na área ambiental, social e econômica (Quadro 3).

Quadro 3: Elementos analisados na tomada de decisão para o desenvolvimento.

\begin{tabular}{|c|c|c|}
\hline IMPACTOS & ÁREA AMBIENTAL & ÁREA SOCIOECONÔMICA \\
\hline \multirow{3}{*}{$\begin{array}{l}\text { Impactos } \\
\text { Positivos }\end{array}$} & $\begin{array}{l}\text { 1. Energia limpa, renovável e } \\
\text { segura. }\end{array}$ & 1. Renda (emprego, impostos, turismo). \\
\hline & $\begin{array}{l}\text { 2. Formação de estoque de água e } \\
\text { lago para recreação. }\end{array}$ & 2. Segurança energética. \\
\hline & $\begin{array}{l}\text { 3. Permite uso de energia } \\
\text { complementar (solar, eólica, etc.). }\end{array}$ & $\begin{array}{l}\text { 3. Recursos alternativos de trabalho e de benefícios na } \\
\text { qualidade de vida. }\end{array}$ \\
\hline
\end{tabular}




\begin{tabular}{|c|c|c|}
\hline & $\begin{array}{l}\text { 4. Centro de referência de } \\
\text { conhecimento (laboratório de flora, } \\
\text { fauna e educação ambiental). }\end{array}$ & $\begin{array}{l}\text { 4. Difusão do conhecimento, do empoderamento de } \\
\text { pensamento sustentável. Ampliação do valor } \\
\text { instrumental dos recursos de flora, fauna e mineral. }\end{array}$ \\
\hline \multirow{6}{*}{$\begin{array}{l}\text { Impactos } \\
\text { Negativos }\end{array}$} & $\begin{array}{l}\text { 1. Irreversibilidade de restauração } \\
\text { do ecossistema. }\end{array}$ & 1. Poucos empregos diretos. \\
\hline & $\begin{array}{l}\text { 2. Prejuízo à hidrologia (barragem } \\
\text { e controle de fluxos artificiais). }\end{array}$ & 2. Sem Compensação Financeira. \\
\hline & $\begin{array}{l}\text { 3. Prejuízo à fauna, à flora e ao } \\
\text { solo. }\end{array}$ & $\begin{array}{l}\text { 3. Carestia durante e após a obra (infraestrutura } \\
\text { insuficiente). }\end{array}$ \\
\hline & $\begin{array}{l}\text { 4. Poluição de GEE (gás carbônico } \\
\text { e metano). }\end{array}$ & 4. Impactos na saúde. \\
\hline & $\begin{array}{l}\text { 5. Alteração no micro clima (ar e } \\
\text { chuvas). }\end{array}$ & 5. Mudanças na dinâmica da produção agropecuária. \\
\hline & $\begin{array}{l}\text { 6. Potencialização dos impactos - } \\
\text { perímetro urbano. }\end{array}$ & $\begin{array}{l}\text { 6. Desequilíbrios na densificação urbana } \\
\text { (superpopulação). }\end{array}$ \\
\hline
\end{tabular}

Fonte: Adaptado do Fundació Fórum Ambiental (2001).

O quadro de impactos da Fundació Fórum Ambiental mostra que "[...] conhecer o valor econômico dos recursos ambientais e determinar sua ordem de prioridade não é suficiente para uma política ambiental. Há que se identificarem os instrumentos que irão ser utilizados para se atingir os objetivos ambientais priorizados" (MOTTA, 2006, p. 75).

Pode-se dizer então, que a viabilidade econômica, de dado processo produtivo, deve passar num primeiro momento pela análise dos recursos disponíveis no intuito de saber qual o impacto socioambiental que sua produção acarretará, e o custo desse impacto no preço final do produto. Esta dimensão visa uma gestão mais harmônica dos fluxos financeiros, com foco macrossocial e não apenas na capacidade de lucro empresarial isolado (CORREA, 2008). Segundo Montibeller-Filho (2001), a dimensão econômica se expõe no manejo eficiente dos recursos, valoração dos custos ambientais pelas organizações e a endogeneização (aumento de suas riquezas sociais locais e da produção sem depender do ambiente externo). Esta dimensão se associa ao SSE quando busca alternativas de explorar os recursos naturais sem destruir, ou pelo menos, interferir de menor forma nos ecossistemas.

No que se refere à dimensão social, Sachs (1993, p. 25) sumariza a mesma como a necessidade de melhorar a qualidade de vida da população mediante a personificação da boa sociedade, a do "ser" e não a do "ter":

A consolidação de um processo de desenvolvimento baseado em outro tipo de crescimento e orientado por outra visão do que é a boa sociedade. O objetivo é construir uma civilização do 'ser', em que exista maior equidade na distribuição do 'ter' e da renda, de modo a melhorar substancialmente os direitos e as condições de amplas massas de população e a reduzir a distância entre os padrões de vida dos abastados e não abastados (SACHS, 1993, p. 25).

Quando se tem exclusão por parte da sociedade, tem-se uma pressão maior na relação com a natureza e sua exploração de maneira exacerbada, suprimindo a capacidade de resiliência dos SSE, pois traz uma relação de desigualdade social que permite e instiga as ações de degradação ambiental. Por fim, a dimensão ecológica, personificada pelo pilar da 
prudência ambiental, tem nas palavras de Montibeller-Filho o elo entre os pilares de sustentabilidade e a principal característica para que se encontre resiliência nos sistemas sócio ecológicos: "O desenvolvimento sob a nova ótica e inseparável da gestão de recursos naturais coloca em primeiro plano a questão de reprodutibilidade das relações entre as sociedades humanas e seu meio ambiente" (MONTIBELLER-FILHO, 2001, p. 51).

\section{AMBIENTALISMO EMPRESARIAL E PRÁTICAS AMBIENTAIS}

Desde os anos 1960, que as organizações vêm reavaliando as formas de gerir os problemas ambientais, buscando novos meios para enfrentar os desafios impostos pelo meio externo. Já em 1970, as corporações viam sua relação com o meio ambiente como uma ameaça externa à lucratividade e às práticas empresariais estabelecidas (HOFFMAN, 2000). Mas, ao longo das três décadas, com a redefinição do papel do Estado, o fortalecimento das ONGs ambientalistas, com as batalhas judiciais e legislativas em torno do meio ambiente e uma crescente atenção da opinião da sociedade civil sobre o tema, ocorreu um amplo processo de mudança, na qual resultaria na origem do chamado ambientalismo empresarial (ABRAMOVAY, 2007). Este movimento fez com que o meio ambiente se tornasse um componente importante na dinâmica das empresas.

Dentro do ambientalismo corporativo, existem cinco momentos diferentes na história, caracterizados pelo realinhamento de interesses no campo organizacional: (i) ambientalismo industrial (1960-1970), que enfatizava a resolução interna de problemas como um adjunto da área de operações; (ii) ambientalismo regulatório (1970-1982), cujo foco era sobre a conformidade com as regulamentações, dada a imposição externa de novas leis ambientais cada vez mais rigorosas; (iii) ambientalismo como responsabilidade social (1982-1988), cujo foco era sobre a redução da poluição e minimização de resíduos dirigidos externamente por associações de indústrias e iniciativas voluntárias; e (iv) ambientalismo estratégico (19882000), no qual se dá ênfase à integração de estratégias ambientais pró-ativas a partir da alta administração e da ação dos competidores; (v) ambientalismo proposital (após 2000) as empresas adotam as práticas de sustentabilidade ambiental, porque entende-se que não faz sentido contribuir para um mundo insustentável (HOFFMAN, 2001; GONÇALVES-DIAS, 2009, apud SEVERO, 2013).

A Figura 3 ilustra os cinco períodos descritos acima, apresentando as fases da mudança no foco da sustentabilidade ambiental na gestão organizacional do meio empresarial, desde os anos de 1960. 
Figura 3: Mudança no foco da sustentabilidade ambiental na gestão organizacional (1960/2005)

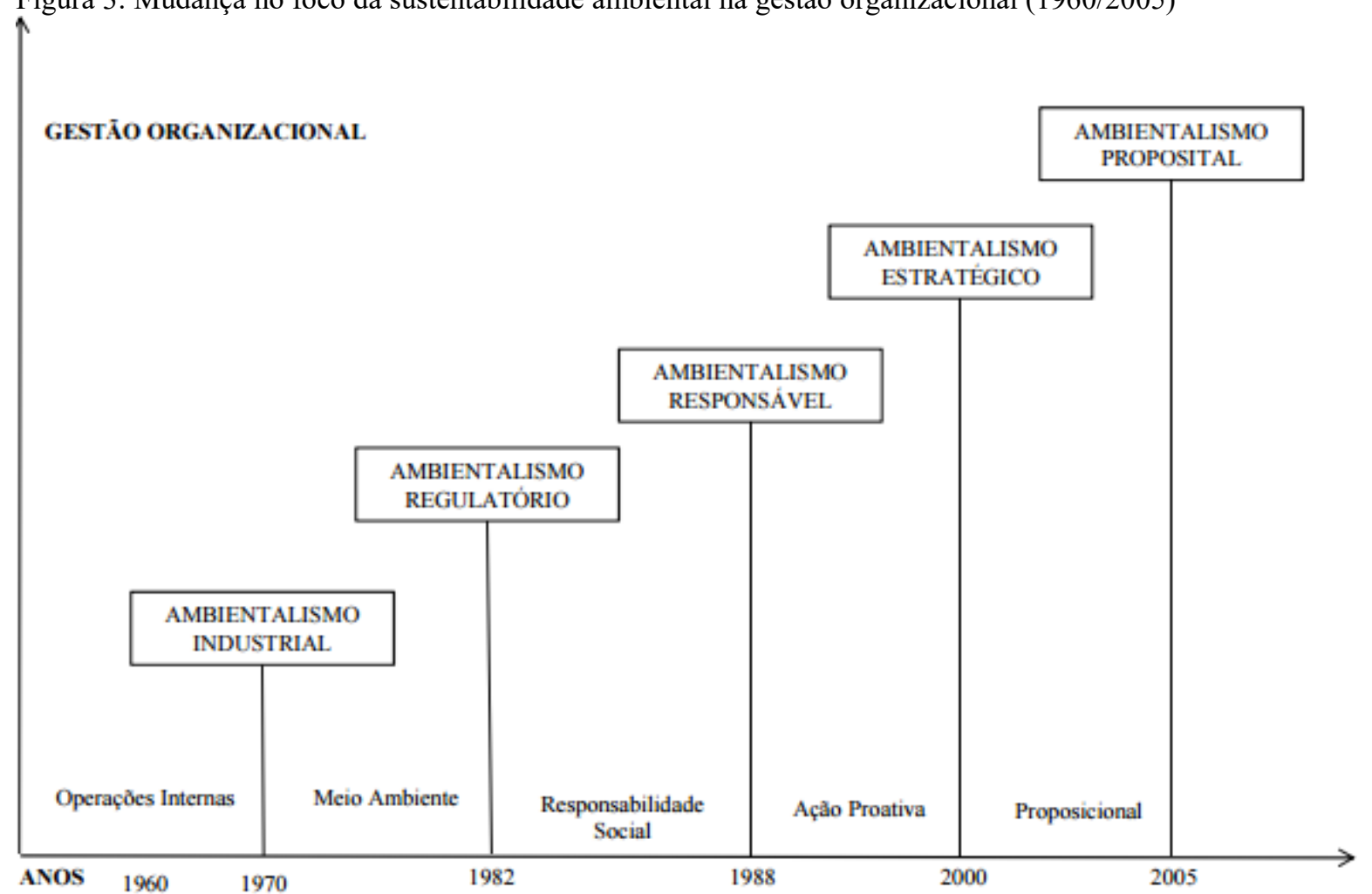

Fonte: Severo (2013, p.82)

Entretanto, os anos 90 foi o período, onde a realidade do ambientalismo dentro das organizações tornou-se mais complexo que a simples conformidade da responsabilidade social ou das leis. De um modo geral, as organizações passaram a atuar sobre novas demandas, tanto no âmbito social quanto ambiental, colocando principalmente o meio ambiente nas estratégias de negócio. Dentro das demandas ambientais, Kinlaw (1997) destaca que as organizações aplicam o que é imposto, desenvolve sua gestão a partir do cumprimento de leis. Sanches (1997) complementa que as respostas das empresas às questões ambientais podem variar muito, pois dependem do tipo de negócio envolvido, dos problemas ambientais decorrentes do setor da atividade, do tamanho da organização e com a complexidade da estrutura corporativa.

Ainda nos anos 90, a realidade do ambientalismo no mundo dos negócios teria se tornado mais complexa que a simples conformidade com as leis ou a responsabilidade social. Proteção ambiental e competitividade econômica estavam se tornando entrelaçadas. Diante dessa nova realidade, o que anteriormente era dirigido por pressões que estavam fora do mundo dos negócios direcionava-se por interesses que existiam nos ambientes econômico, político, social e mercadológico das empresas (DIAS, 2011, p. 6).

Diante das pressões legislativas, é natural que a intensa regulamentação imponha desafios de mudança nas organizações. O ponto chave desta discussão, é a busca constante por processos que visem à inovação ambiental. A figura 4 ilustra os principais fatores que influenciam no comportamento ambiental das organizações, sendo estas, as variáveis propulsoras da adoção de estratégias que minimizam o impacto ambiental. 
Figura 4: Pressões para a adoção de estratégias ambientais nas organizações.

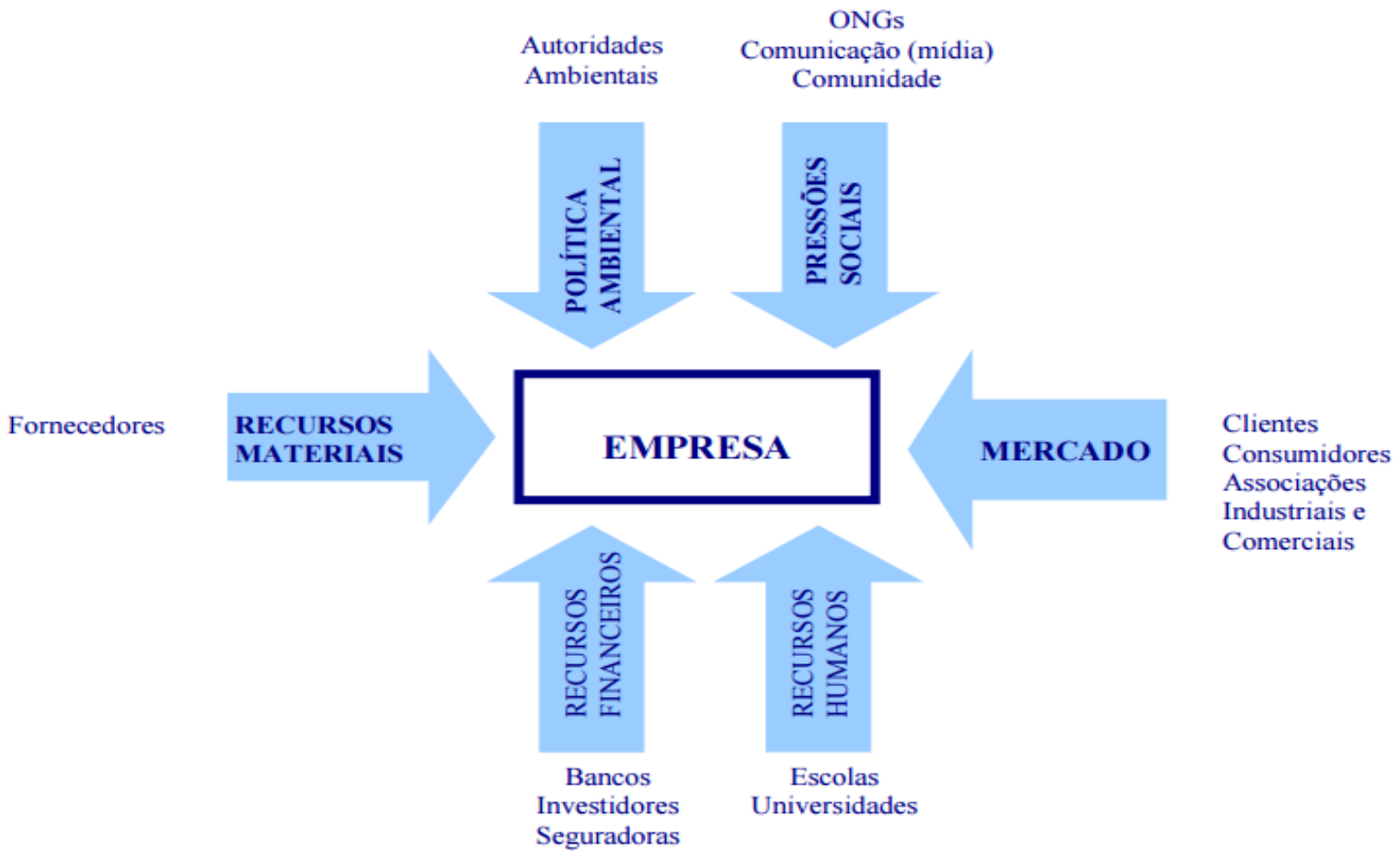

Fonte: Antunes, Santos e Lobo (2003, p. 34)

A postura ambiental proativa por parte das organizações resulta em uma transformação da cultura organizacional e consequentemente em sua sustentabilidade perante aos mercados. Neste cenário, são exigidos periodicamente das organizações relatórios de sustentabilidade, cujo principal interessado em saber das informações é o mercado. Com isso é preciso de estratégias e diretrizes na construção destes relatórios. $\mathrm{O}$ objetivo principal dos relatórios é demostrar a partir dos principais indicadores, o desempenho econômico, ambiental e social das organizações. Existem hoje vários órgãos que estabelecem esses indicadores de desempenho tanto ambiental quanto social, na qual destacam-se como principais o Instituto Ethos e o Índice de Sustentabilidade Empresarial (ISE BM\&FBOVESPA) a nível nacional e a nível internacional tem-se o Índice Dow Jones Sustainability World Indexes e a Global Reporting Initiative

É necessário destacar as ações relacionadas às práticas ambientais, cujo objetivo é ajudar na obtenção de um bom desempenho organizacional no quesito socioambiental. Dessa forma, as práticas ambientais são ferramentas que atestam as ações ambientais das organizações, onde os maiores interessados são os consumidores, fornecedores, governos, dentre outros stakeholders envolvidos. Todavia, surge a discussão na qual circunda a norma internacional ISO 14001. Esta norma define os requisitos para estabelecer e operar um sistema de gestão ambiental. O que transparece por meio desta normativa é que as organizações podem estar preocupadas tanto com a lucratividade da atividade, como também com a gestão ambiental.

No meio empresarial há inúmeras práticas que são desenvolvidas pelas empresas, tais como, sistema de gestão de resíduos, práticas de produção mais limpa, sistema de gestão ambiental, tratamentos de efluente e reciclagem, sendo estas as práticas mais comuns realizadas pelas empresas. Portanto, as adoções de práticas ambientais por parte das empresas 
resultam em tese numa minimização dos recursos naturais utilizados no processo produtivo. Dessa forma, partindo-se das abordagens sobre sistema sócio ecológico e ambientalismo no contexto empresarial, percebe-se que todas as discussões levam para as práticas de preservação do meio ambiente, além do bem-estar das comunidades envolvidas. Este estudo não esgota todas as possibilidades de discussões, sendo conceitos que estão em constantes mudanças e adaptações no contexto das organizações.

\section{CONCLUSÕES}

Elaborar e estabelecer planos de desenvolvimento socioeconômico de forma sustentável tornou-se um grande desafio da atualidade devido à pluralidade de atores e contextos territoriais. Porém, o desenvolvimento com base na sustentabilidade promove mudanças que precisam de constantes adaptações. Com isso surge a necessidade de se desenvolver políticas adequadas, redimensionamento dos setores produtivos e estudos aprofundados, no que diz respeito ao desenvolvimento territorial sustentável, buscando a harmonia entre a sociedade e o meio ambiente.

A busca por um crescimento mais sustentável tem a ver como tornar os processos produtivos de crescimento mais eficientes do ponto de vista dos recursos naturais. Do ponto de vista do desenvolvimento regional, a conservação ambiental é importante e necessária para o desenvolvimento e o crescimento econômico em longo prazo, pois ambos estão interligados, tendo assim, uma relação de dependência no atual contexto produtivo. Todavia, nestas últimas décadas surgiram várias estratégias de crescimento verde, propostas por empresas de vários segmentos de mercado, visando assim aumentar o capital natural além de evitar a degradação ambiental.

Embora esse tipo de desenvolvimento não seja algo novo, o seu processo de planejamento e mudança nesta esfera é significativamente inovador e positivo. Dessa forma, as estratégias empresariais precisam de novas táticas multidisciplinares, para que se consiga soluções admissíveis quanto aos problemas ambientais. Entender os fundamentos da resiliência, um processo importante no que tange o desenvolvimento de estratégias de conservação ambiental. Portanto, discutir o desenvolvimento sustentável somente a partir das teorias não é um avanço significativo quanto ao seu entendimento. Mas discutir as novas metodologias, práticas e formas alternativas de desenvolvimento que visam mensurar algum tipo de sustentabilidade é importante, pois a partir deste contexto, surgem caminhos alternativos para se atingir o desenvolvimento sustentável desejado.

\section{REFERÊNCIAS}

ABRAMOVAY, R. Para uma teoria dos estudos territoriais. In: Ortega, A.C.; Almeida Filho, N.(Orgs.). Desenvolvimento territorial, segurança alimentar e economia solidária.

Campinas: Ed. Alínea, 2007. 
ANTUNES, P; SANTOS, R; LOBO, G. Estratégias ambientais das empresas do sector electro. Lisboa: Centro de Economia Ecológica e Gestão do Meio Ambiente, Universidade Nova de Lisboa, 2003.

BIGGS, R.; SCHLUTER, M.; SCHOON, M. L. Principles for building resilience: sustaining ecosystem services in Social Ecological Systems. Cambridge: Cambridge University Press, 2014.

BM\&FBOVESPA. Disponível em: <https://www.rad.cvm.gov.br/ENETCONSULTA/ frmGerenciaPaginaFRE.aspx?NumeroSequencialDocumento $=63698 \&$ CodigoTipoInstituicao $=2>$. Acesso em: 10 abr. 2017.

BRANDÃO, A. C. Teorias, estratégias e politicas regionais e urbanas recentes: anotações para uma agenda do desenvolvimento territorializado. Revista Paranaense de Desenvolvimento. Curitiba, n 10, p.57-76, 2004.

CAPRA, F.; LUISI, P. L. A visão sistêmica da vida: uma concepção unificada e suas implicações filosóficas, políticas, sociais e econômicas. São Paulo: Cultrix, 2014.

DIAS, Reinaldo. Gestão ambiental: responsabilidade social e sustentabilidade. 2. ed. São Paulo: Atlas, 2011.

FARRALL, M. H. O conceito de resiliência no contexto dos sistemas socio-ecológicos. Revista Online da Sociedade Portuguesa de Ecologia, n. 6, p. 50-62, 2012.

FENECH, F. C. Presentación y evaluación de la contabilidade social y medioambiental. Curso de verano de la Universidade de Burgo, 2002. Disponível em: $<$ www.ubu.es $>$. Acesso em: 19 jan. 2017.

FONSECA, M. C. L. Para além da pedra e cal: por uma concepção ampla do patrimônio cultural. In: ABREU, Regina, CHAGAS, Mário (orgs.). Memória e patrimônio: ensaios contemporâneos. Rio de Janeiro: DP\&A, 2003, p. 56-76.

FUNDACIÓ FÓRUM AMBIENTAL. Agencia Europea del Médio Ambiente. Barcelona, abril de 2001. Perfil profesional del responsable de medio ambiente en las organizaciones. 2016. Disponível em: <www.forumambiental.com>. Acesso em: 27 fev. 2017.

GIL, A. C. Como elaborar projetos de pesquisa. 5. ed. São Paulo: Atlas, 2010.

GODARD, O. A gestão integrada dos recursos naturais e do meio ambiente: conceitos, instituições e desafios de legitimação. In: P. F. VIEIRA, P. F. e WEBER, J. (Orgs.). Gestão de recursos naturais renováveis e desenvolvimento. Novos desafios para a pesquisa ambiental. São Paulo: Cortez, 1997.

GONÇALVES-DIAS, S. L. F. Catadores: uma perspectiva de sua inserção no campo da indústria de reciclagem. Tese (Doutorado em ciências ambientais) - Programa de PósGraduação em ciências ambientais. Universidade de São Paulo (USP), São Paulo, 2009. p. 298. 
HERRERA, A. Novo enfoque do desenvolvimento e o papel da ciência e da tecnologia. In: DAGNINO, R.; THOMAS, H. Ciência, Tecnologia e Sociedade: uma reflexão latinoamericana. Taubaté: Cabral Editora e Livraria Universitária, 2003, p. 25-45.

HOFFMAN, A. J. From heresy to dogma: an institutional history of corporate environmentalism. Stanford, Stanford Business Books, 2001.

INAYATULLAH, S. Comunicação e mudança nos países em desenvolvimento. Tradução por Maria Heloiza Shalbs Capellato. São Paulo: Melhoramentos, 1973, p. 114-118;

KINLAW, D. C. Empresa competitiva e ecológica: desempenho sustentado na era ambiental. São Paulo. Makron Books, 1997.

LARRIÉRE, C. e LARRIÉRE, R. Du bon usage de la nature. Pour une philosophie de l'environnement. Paris: Aubier, 1997.

MONTIBELLER FILHO, G. O mito do desenvolvimento sustentável: meio ambiente e custos sociais no moderno sistema produtor de mercadorias. Florianópolis: Editora da UFSC, 2001.

MOTTA, R. S. Economia ambiental. Rio de Janeiro: Editora FGV, 2006.

OLIVEIRA, G. B. Uma discussão sobre o conceito de desenvolvimento. Revista da FAE, Curitiba, v. 5, n. 2. p. 37-48, maio/agosto/2002.

ROSSETTI, J. P. Introdução à economia. 18. ed., reest. atual. e ampl. São Paulo: Atlas, 2000 .

SACHS, I. Estratégias de transição para o século XXI: Desenvolvimento e meio ambiente. Tradução Magda Lopes. São Paulo: Studio Nobel, 1993.

SANCHES, C. S. Evolução das práticas ambientais em empresas industriais: um modelo genérico. In: ENCONTRO NACIONAL SOBRE GESTÃO EMPRESARIAL E MEIO AMBIENTE, 5., 1997, São Paulo. Anais... São Paulo: Fundação Instituto de Administração da Universidade de São Paulo/ Fundação Getúlio Vargas, 1997, p .43-62.

SANTOS, F. T. Resiliência Estratégica para um Desenvolvimento Regional Sustentável. Revista Portuguesa de Estudos Regionais, n. 20, p. 29-40, $1^{\circ}$ Quadrimestre, 2009.

SANTOS, E. L.; BRAGA, V.; SANTOS, R. S.; BRAGA, A. M. S. Desenvolvimento: Um Conceito Multidimensional. Desenvolvimento Regional em debate, a. 2, n. 1, p. 44-51, jul. 2012.

SCATOLIN, F. D. Indicadores de desenvolvimento: um sistema par o estado do Paraná. 1989. Dissertação (Mestrado em Economia) - Universidade Federal do Rio Grande do Sul. Porto Alegre: UFRGS, 1989. 
SEVERO, E. A. Inovação e sustentabilidade ambiental nas empresas do arranjo produtivo local metal mecânico automotivo da serra gaúcha. 2013. 234 f. Tese

(Doutorado em Administração). Pontifícia Universidade Católica do Rio Grande do Sul. Caxias do Sul: PUC, 2013.

VERGARA, S. C. Projetos e relatórios de pesquisa em administração. 12. ed. São Paulo: Atlas, 2010.

Artigo recebido em: 01/08/2017

Artigo aprovado em: 19/10/2017 